\title{
CUANDO SER INDIO NO RINDE: SOCIEDAD POLÍTICA, PARTICULARISMO Y EXCEPCIÓN EN LAS NARRATIVAS NACIONALES DEL URUGUAY ${ }^{1}$
}

\author{
SILVINA MERENSON ${ }^{2}$ \\ UNSAM/CONICET
}

\begin{abstract}
RESUMEN: El presente artículo analiza las relaciones entre sociedad política, particularismo y excepción en las narrativas nacionales del Uruguay. Para ello toma un evento reciente: la primera ocupación de tierras que tuvo lugar en la ciudad fronteriza de Bella Unión, protagonizada por un grupo de trabajadores rurales sindicalizados autodenominados "peludos". A partir de las identificaciones propuestas para este colectivo, especialmente la que buscó emparentarlos con "los charrúas", el texto explora el lugar que cabe al empleo de clasificaciones y categorías étnicas en la construcción de la agencia subalterna.
\end{abstract}

PALABRAS CLAVE: categorías étnicas; identificaciones; sociedad política; narrativa nacional.

ABSTRACT: This article analyzes the relations among political society, particularism, and exception in the national narratives of Uruguay. In this way, I consider a recent event: the first occupation of land held in the border town of Bella Union carried out by a group of unionized rural workers who called themselves "peludos". On the basis of different identifications proposed for this group, especially that which tried to relate the "peludos" to the "charruas", this paper explores the importance of using classifications and ethnic categories in the construction of the subaltern agency.

KEYWORDS: ethnic categories; identifications; political society; national narrative.

Como es sabido, a lo largo del siglo XX, el "lenguaje de la clase" (SIGAUD, 2004) estructuró las identidades, las luchas políticas y, en buena medida, algunos de los debates más importantes de las ciencias sociales. Sin embargo, en las últimas décadas, este lenguaje fue siendo

\footnotetext{
${ }^{1}$ Este texto es una reelaboración de la ponencia presentada en el marco del Workshop "Identidades en transición” desarrollado en la Universidad Nacional de San Martín el día 8 de octubre de 2010. Agradezco los valiosos comentarios que en dicha oportunidad recibí de Sergio Baptista da Silva, Claudia Briones y Alejandro Grimson.

2 Magíster en Antropología Social (IDES/IDAES-UNSAM) y Doctora en Ciencias Sociales (IDES/UNGS). Docente de la Universidad Nacional de San Martín y becaria posdoctoral de CONICET, Argentina. E-mail: smerenson@ unsam.edu.ar .
}

Espaço Ameríndio, Porto Alegre, v. 4, n. 2, p. 172-190, jul./dez. 2010. 
sustituido por el énfasis puesto en "las exclusiones e inclusiones en el estudio de las desigualdades" (STOLCKE, 2006, p. 125). Las demandas por la inclusión tramadas en las políticas de las identidades - muchas veces retocadas, adaptadas o construidas - sirvió como soporte de múltiples y diversos reclamos (Cf. SEGATO, 2007). Fue en este contexto que la etnicidad ganó importancia en el activismo político, en las políticas emprendidas por el Estado y en el discurso público. En toda la región diversos movimientos encontraron en la revitalización y "marcación" (BRIONES, 1998) de la etnicidad una clave para las demandas de autodeterminación y autonomía, para el reconocimiento de las diferencias culturales, lingüísticas y de los distintos derechos colectivos que se vieron plasmados en las reformas constitucionales de muchos de los países de la región.

En tanto horizonte de sentido, la comprensión multiétnica tuvo implicancias directas en lo que respecta a las definiciones de nociones como "'territorio", "cultura" y "sujeto de derecho", entre otras. Sin embargo, la explosión de identidades particulares, no siguió siempre el mismo camino, sino que éste estuvo delimitado contextos locales y nacionales. Esta última escala - la nacional - en tanto proyecto, discurso o evaluación que organiza nuestra visión del mundo, parecería cobrar fuerza en tiempos de globalización y discursos acerca de la progresiva homogeneización cultural (CALHOUN, 2007, p. 13). Considerar esto último implica asumir lo ya sabido: que las diferencias culturales no pueden ser advertidas en el vacío, sino en la dinámica histórica que hace "que la percepción de la negritud y de la indianidad en cada uno de los países del continente varíe en función de lógicas históricas propias" (SEGATO, 2007, p. 20). En este sentido es que los ecos que encuentra "el retorno del indio" (ALBÓ, 1991) o el "indio fantasma" (LÁZZARI, 2007) puede enmarcar y constituir un punto de partida para la exploración de la nación como espacio de interlocución o "campo de posibilidad" (GRIMSON, 2007). Sólo a título de ilustración, aunque como se verá pertinente a este texto, podemos señalar que la construcción del colectivo "charrúa" y su reciente reconocimiento por parte de la FUNAI en Brasil (Cf. BAPTISTA DA SILVA et. al, 2008) es sensiblemente distinta del tratamiento que esta marcación étnica encuentra en el Uruguay, donde además no existe una institución semejante a la mencionada. 
Este artículo trabaja sobre el lugar que cabe, en la construcción de la agencia subalterna, al empleo de algunas de las clasificaciones y categorías étnicas disponibles en el contexto nacional uruguayo. Para ello es que abordamos un proceso bastante reciente en la ciudad de Bella Unión, emplazada en la única frontera que Uruguay comparte con Brasil y Argentina; reconocida, desde mediados de la década de 1940, por la que es su principal actividad económica: la agroindustria azucarera3.

En lo que sigue voy a referirme a un evento en el que "el indio", "lo indio", no resultó parte del marco de interlocución legítimo o legitimado por los/as protagonistas de una demanda de tierras. El objetivo de nuestro recorrido no será apuntar - y mucho menos concluir - que la utilización de estas clasificaciones y categorías étnicas carecen de relevancia en la construcción de la agencia subalterna. En cambio buscaremos preguntarnos por aquellos casos en los cuales desconocer esta marcación es, justamente, lo que trama la agencia de los sectores subalternos poniendo en evidencia las largas y complejas trayectorias seguidas por estas categorías y clasificaciones en el Uruguay. Cabe señalar que esto, de ninguna manera, implica sostener que los/as protagonistas del evento que analizaré a continuación "deberían" haber asumido tal adscripción. Se trata, en cambio, de explicar algunas de las razones por las cuales no lo hicieron para ofrecer una lectura posible del modo en que operan los vínculos entre sociedad política, particularismo y excepción en las narrativas nacionales uruguayas.

\section{La ocupación de tierras y la desamortiguación de una narrativa nacional}

El 15 de enero de 2006 unas 50 personas vinculadas a la Unión de Trabajadores Azucareros de Artigas (UTAA), el Sindicato de Obreros de

\footnotetext{
${ }^{3}$ Bella Unión se encuentra situada en el extremo noroeste del país, en el departamento de Artigas, a 640 kilómetros de la capital nacional. Está emplazada en la confluencia del río Uruguay (que define el límite territorial con la ciudad de Monte Caseros, provincia de Corrientes, República Argentina) y el río Cuareim (que define el límite territorial con Barra do Quaraí, Estado de Rio Grande do Sul, Republica Federativa de Brasil). El censo de 1963 indicó que Bella Unión tenía 9.983 habitantes, siendo su densidad de población 4 veces superior a la densidad de todo el departamento. Según el censo agropecuario de 1961 la superficie sembrada con caña era de casi 3.000 hectáreas. Los últimos datos censales (2004) registran para Bella Unión 13.187 habitantes, mientras que el área de caña entre 2007 y 2009 se ubica entre las 6.000 y las 7.000 hectáreas.
}

Espaço Ameríndio, Porto Alegre, v. 4, n. 2, p. 172-190, jul./dez. 2010. 
Calnu Artigas (SOCA) y la Asociación de Pequeños Agricultores y Asalariados Rurales de Bella Unión (APARBU) ocuparon una chacra de 36 hectáreas situada a 8 kilómetros de la ciudad, adjudicada a un "colono" por el Instituto Nacional de Colonización que, desde hacía más de 10 años, mantenía improductivo el predio.

Esta medida, rápidamente, conquistó las portadas y titulares de todos los medios de prensa que la refirieron como "la primera ocupación de tierras de la historia moderna del Uruguay" (ABELANDO, 2006, p. 67). Pero no sólo su carácter "inédito" o "innovador" era lo que aparecía como una constante en las notas, editoriales y debates televisivos de mayor audiencia. A ello se sumaba el contexto político en el que se produjo la medida y la caracterización de sus protagonistas. Periodistas, intelectuales y analistas políticos no dejaban de señalar que la ocupación de tierras tenía lugar a tan sólo 10 meses de la asunción presidencial del Dr. Tabaré Vázquez, es decir a poco del inicio de la primera gestión de la coalición de izquierda Frente Amplio (FA) de la historia uruguaya. Más aún, la ocupación se produjo a escasos 10 días de concretarse el traspaso formal del ingenio local - CALNU 4 - a la órbita estatal. A 10 días, entonces, de lo que era presentado como el primer paso hacia el nuevo emprendimiento sucro-alcoholero, punta de lanza del "Uruguay Productivo", nominación que recibió el proyecto político en que el FA basó su campaña electoral.

Pero si era difícil entender que esta ocupación de tierras se produjera durante la primera gestión frenteamplista de la historia política del país, más difícil aún era comprender que esta ocupación sea protagonizada por "los peludos de Bella Unión" quienes, además de contar con un gabinete nacional integrado por figuras sumamente cercanas a la trayectoria de su sindicato - la UTAA ${ }^{5}$-, era (y es) uno de los actores más emblematizados por la izquierda desde comienzos de la década de 1960.

\footnotetext{
${ }^{4}$ La sigla corresponde a Cooperativa Agraria Limitada del Norte Uruguayo.

${ }^{5}$ Entre ellos: José Díaz, antiguo abogado del sindicato y en ese entonces ministro del interior; José Mujica, ex miembro de la dirección del MLN-T, en ese entonces ministro de agricultura y actual presidente de la nación; y Raúl Sendic hijo, hijo del máximo referente del MLN-T y por ese entonces futuro director ALUR, el nuevo emprendimiento sucro-alcoholero.
}

Espaço Ameríndio, Porto Alegre, v. 4, n. 2, p. 172-190, jul./dez. 2010. 
"Los peludos" 6 , tal como se autodenominan los hombres y mujeres empleados/as en el corte de la caña de azúcar, tanto como la creación y la trayectoria de su sindicato, operan como una suerte de protohistoria del Movimiento de Liberación Nacional Tupamaros (MLN-T) a partir de la trayectoria de Raúl Sendic ${ }^{7}$, el máximo líder de esta organización revolucionaria que fuera la más importante del Uruguay entre los años sesenta y setenta. Para el MLN-T y para otros sectores de la izquierda (como el Partido Socialista y el Partido Comunista) "los peludos" fueron parte de la evidencia empírica disponible que permitió poner en cuestión el relato del Uruguay como la "Suiza de América". Esto es la descripción del país en la excepcionalidad que indicaba, en el contraste, al resto de los países latinoamericanos como más "atrasados" tanto por la presencia en ellos de "población indígena", como por el "alcance dispar del Estado en materia de asistencia social y legislación laboral" y la existencia en ellos de "marginaciones socioculturales traumáticas" (CAETANO y RILLA, 1998, p. 178).

Desde principios de la década de 1960, las condiciones de vida y de trabajo en las azucareras, la lucha sindical $y$, especialmente las 5 marchas realizadas por la UTAA hacia Montevideo ${ }^{8}$, fueron los eslabones de una cadena que definió para "los peludos" una serie de representaciones que, entre el miserabilismo y la épica, los indicó como el reverso del "país de excepción", contribuyendo con ello a la latinoamericanización de la izquierda y a la ubicación del Uruguay en la senda señalada por las luchas revolucionarias en el continente. En esta tarea, por distintas vías, de diversas formas, y a lo largo del tiempo "los peludos de Bella Unión" fue el único grupo social pasible de ser emparentado con "la criollada desposeída" que luchó junto a Artigas en las guerras del siglo XIX, con los "gauchos" que pelearon con Aparicio

\footnotetext{
${ }^{6}$ La palabra "peludo", producto de la analogía con un roedor de la zona llamado de este modo, (auto)designa tanto a los actuales como a ex cortadores de caña de azúcar, a los miembros de sus familias y a quienes aún no habiendo trabajado en el corte de caña, se llaman de este modo, ya sea porque pertenecen al mismo sector sociodemográfico que los cortadores o porque "trabajan en la tierra", aunque en otra rama productiva.

${ }^{7}$ Raúl Sendic (1925-1989) fue el máximo referente del MLN-T desde su creación, en 1966. En 1956 se incorporó al Partido Socialista y, en los años sucesivos, participó de la conformación de varios sindicatos rurales, entre ellos, la UTAA.

8 Las marchas tuvieron lugar en los años 1962, 1964, 1965, 1968 y 1971. Todas ellas unieron Bella Unión con Montevideo.
}

Espaço Ameríndio, Porto Alegre, v. 4, n. 2, p. 172-190, jul./dez. 2010. 
Saravia9 a principios del siglo XX, con los "soldados de Prestes", los "guajiros" cubanos, el "campesinado", los "excluidos" y los "negros africanos" como caso paradigmático de extrema pobreza10.

Fue hacia mediados de los años '80, en consonancia tanto con el pasaje del "lenguaje de la clase" a las "políticas de la identidad" como con el fin de la dictadura cívico-militar (1973-1985), que "los peludos" quedaron extraordinariamente filiados con el modo en que Magariños Cervantes, en 1848, describía a la montonera en "Caramurú", la novela que dio forma al "protoimaginario de la nación" (BURGUEÑO, 2000, p. 41). Condensando lo mejor de la sociogénesis de la nación, como una suerte de tipo ideal wolfiano, "los peludos" fueron paradójicamente incorporados al relato nacional asumiendo los rasgos blanqueados que, entre otras cuestiones, los volvió sujeto de derecho; íconos en la escala local del proceso de radicalización política experimentado por el país en los años '60, recuperado en los '80 como parte de la inserción del MLNT en el sistema democrático y su "conversión ético-política" (GARCÉ, 2006). Tal vez esta breve síntesis nos ayude a comprender por qué no se hicieron esperar las acusaciones de "traición" y "oportunismo" que desde algunos sectores del oficialismo recayeron sobre los/as ocupantes, señalando el carácter "aislado" de la demanda o su origen capitalino como forma de invalidar o cuestionar su "autenticidad".

Por la tierra y con... ¿quién?

En rigor, la demanda de tierras y la lucha por la Reforma Agraria forma parte de la agenda de la UTAA desde al menos 1964, cuando el sindicato definió la consigna "Por la tierra y con Sendic" para sus cuatro marchas hacia la capital del país, en las que pidieron la expropiación de casi 33.000 de hectáreas improductivas cercanas a la ciudad de Bella

9 Considerado por la historiografía "el último caudillo rural”, Aparicio Saravia (1856-1904) protagonizó el último gran alzamiento armado contra un gobierno constituido. Su muerte, en 1904, señala el inicio de la historia moderna del país.

10 Para 2003 los índices de desnutrición y mortalidad infantil en Bella Unión dieron los números más elevados del país. Estos indicadores, que según la prensa igualaban a los registrados en Camboya, Ghana, Kenia y Camerún, pusieron el acento en las secuelas de la miseria, expresada también en una nueva epidemia de hepatitis A declarada entre los últimos meses de 2004 y el verano de 2005. La ciudad de Bella Unión, entonces, fue presentada como emblema de la injusticia nacional y, por ende, como síntesis del desafío que enfrentaría la nueva gestión de gobierno.

Espaço Ameríndio, Porto Alegre, v. 4, n. 2, p. 172-190, jul./dez. 2010. 
Unión. Pero más allá de este antecedente nunca antes la militancia sindical de Bella Unión había protagonizado una ocupación. No lo hizo en los años '60, cuando encarnaba el motor de la revolución social y negociaba con la izquierda uruguaya su presentación como "campesinado" o "proletariado rural"11. Tampoco en los años '80 y '90, cuando las terribles consecuencias del proceso de reconversión productiva experimentado por la agroindustria azucarera y el ingreso del país en el Mercosur amenazaban con terminar definitivamente con esta industria en Uruguay y "los peludos" comenzaban a presentarse como "pobres" o "excluidos".

Como suele suceder, lo que resultaba difícil de comprender para distintos sectores y actores sociales identificados con el nuevo gobierno encontraba en "los peludos" una explicación bastante evidente: "hoy", decían, "hay más espacio para luchar". La medida, entonces, fue parte de la brecha abierta por la nueva coyuntura política y fue parte del éxito de los/as ocupantes para imponer una demanda que, si bien no era nueva, fue planteada en un nuevo formato provisto por la "sociedad política" (CHATTERJEE, 2007). Es decir por la posibilidad de presentarse como un grupo con un interés particular que buscó ser interpelado fragmentariamente por el Estado. Las claves de este nuevo formato fueron la implementación de medidas "para- legales" para satisfacer las demandas y, fundamentalmente, la importancia de la "comunidad" como espacio de agenciamiento (CHATTERJEE, 2007).

Esto último arroja las primeras pistas para tratar de explicar las razones por las cuales, en el primer comunicado de prensa, los protagonistas de la ocupación se presentaron como "peludos de Bella Unión", revistiendo con las características de un grupo lo que en verdad era un conjunto de personas sumamente heterogéneo, vinculado por redes políticas, religiosas y vecinales. "Peludo", entonces, garantizaba la particularidad de esta demanda de un modo hasta entonces inédito y particularizaba, también de un modo inédito, al interlocutor del reclamo: el Estado sobre el que los/ as ocupantes inscribían los sentidos asignados al rol un "gobierno compañero". Para estos/as renovados/ as "peludos" la

11 "Campesino", en este contexto, funcionó de un modo semejante al mencionado por Chacrabarty (2008), es decir como representación de "todo aquello que no es burgués (en sentido europeo) en la modernidad y el capitalismo" (CHACRABARTY, 2008, p. 38).

Espaço Ameríndio, Porto Alegre, v. 4, n. 2, p. 172-190, jul./dez. 2010. 
demanda de tierras no era el camino hacia la revolución, sino la puerta de acceso a su inclusión en el "Uruguay Productivo". Parafraseando a Vich, "los peludos" devenidos/as "ocupantes" procuraban con esta medida "un espacio para condicionar y definir no cómo gobernar, sino cómo querían ser gobernados" (VICH, 2007, p. 18)12.

Al mismo tiempo en que "los peludos" enfrentaban las críticas y acusaciones apuntadas surgía la solidaridad desde otros actores y sectores sociales. Fue entonces que se conformó la Comisión de Apoyo por Tierra (CAXT)13. Para la CAXT la suerte de la demanda no se jugaba en el diálogo con el "gobierno" o con la dirigencia política, sino en la amplia difusión de la medida. Con este objetivo creó una página en Internet en la que publicó notas, reportajes, fotos, comunicados y recibió mensajes. Esta página, con más de 1000 mensajes, fue transformándose en un espacio no sólo de adhesión o crítica en torno de la ocupación. También reunió los más diversos sentimientos y sensaciones respecto del país y de sus habitantes que buscaron reconocer en "los peludos" diversos rasgos y cualidades. En su conjunto y en líneas generales, lo que allí puede leerse son las fisuras que en los últimos años presenta la caracterización de la sociedad uruguaya como una "sociedad amortiguadora", es decir como una sociedad consensual, en la que "los conflictos [y] las tensiones son, de alguna manera más manuables, más enjuagables que en sociedades globales de gran densidad o asentadas sobre vastos territorios" (REAL DE AZÚA, 2000, p. 15).

Muchas de las personas que se sintieron convocadas a dejar un mensaje en esta página web14 afirmaban que "los peludos están haciendo patria e historia"; que "todavía sigue dando criollos este país" y se mostraban orgullosos de "los orientales que no agachan la cabeza, contra los mediocres que no merecen la nacionalidad que dicen honrar".

\footnotetext{
${ }^{12}$ En este sentido pueden resultar esclarecedoras las declaraciones de uno de los militantes de la UTAA que participó de la ocupación: "en estos últimos tiempos estábamos viendo, con mucho peligro, que los trabajadores rurales y zafrales de la zona estábamos quedando, de alguna manera, fuera de ese proyecto [sucro-alcoholero]. Entonces viendo unas parcelas de tierra que estaban abandonadas de hace un tiempo largo y con la idea fija de instalar cuatro o cinco familias a vivir, fue el disparador de la tomada de estas tierras" (TRABAJO y UTOPÍA, 2006, p. 8).

13 Integrada por gran parte de la militancia universitaria, ex militantes del MLN-T vinculados a la UTAA desde su fundación, militantes sociales pertenecientes a distintas ONGs, y algunas de las agrupaciones políticas de izquierda no integradas al FA.

${ }_{14}$ Todos los mensajes se citaremos a continuación encuentran disponibles en: http://caxtierra.blogia.com/temas/mensajes-recibidos-y-adhesiones.php. Acceso en 2 nov. 2010.
}

Espaço Ameríndio, Porto Alegre, v. 4, n. 2, p. 172-190, jul./dez. 2010. 
Otros mensajes ofrecían relecturas de la historia nacional para ponerlas en relación con la propuesta del nuevo gobierno: "lo que están haciendo los peludos es ni más ni menos que reivindicar el Reglamento de Tierras de 1815 que nuestro padre Artigas nos legara". También, aunque no eran los predominantes, estaban aquellos mensajes que evocaban la historia emblemática de la UTAA y, en tonos sumamente emotivos, deseaban que "el recuerdo de Sendic dirija el machete contra la caña y la opresión", afirmaban que "los peludos de hoy y de siempre son una antorchita que nos guía por el camino de los oprimidos", o saludaban la medida solicitándoles que "inauguren el 'Uruguay Productivo' de pesado, porque no están solos y la cosecha la aseguramos entre todos".

Pero no todos los mensajes eran adhesiones ni tenían el mismo tono de los anteriores. La página web también mostraba la indignación o la irritación de quienes los acusaban a los/as ocupantes de ser "quienes van a hacer que vuelvan los colorados y blancos"15, señalándolos/as como "los culpables de que TODOS los uruguayos hayamos padecido gobiernos que durante los últimos 30 años han saqueado a este país". Entre estas lecturas que indican el modo en que la ocupación reactivó una serie de sentimientos y de distintos posicionamientos vinculados a la marcha del Uruguay, veamos algunos mensajes en particular:

Debemos saberlo, estas manos vienen de abuelos cañeros, son manos que piden la Bella Unión, son de nada menos que de Flores, de Chamangá. Es legado escrito en ocre, que pervive hasta hoy, desde donde nacen los arriesgados flecheros, donde rasca la garra el "peludo".

En recuerdo a Vaimaca Perú (Cacique), Tacuabé (Cacique), del Doctor Chamán Senaqué, de Guyunusa y su hija Igualdad, todos hermanos de la gran Nación Charrúa, torturados en Francia por los mismos autoritarios ancestrales criollos, hasta nuestros días, repitiendo historias. Este Uruguay, nacido de la usurpación de las tierras por medios militares (...), siempre en guerra por la tierra prometida. Siempre la misma mentira, siempre la misma patraña, no va más. Apoyamos en un todo a los peludos (...) En la lengua perdida: BASQUADÉ INCHALA, ( ¿LEVANTATE HERMANO!).

\footnotetext{
15 "Blancos" y "colorados" son las nominaciones que identifican al Partido Colorado y el Partido Blanco o Nacional. Surgidos al calor de las guerras civiles, a fines del siglo XIX, se trata de los dos partidos tradicionales que gobernaron al país alternativamente hasta el año 2004.
}

Espaço Ameríndio, Porto Alegre, v. 4, n. 2, p. 172-190, jul./dez. 2010. 


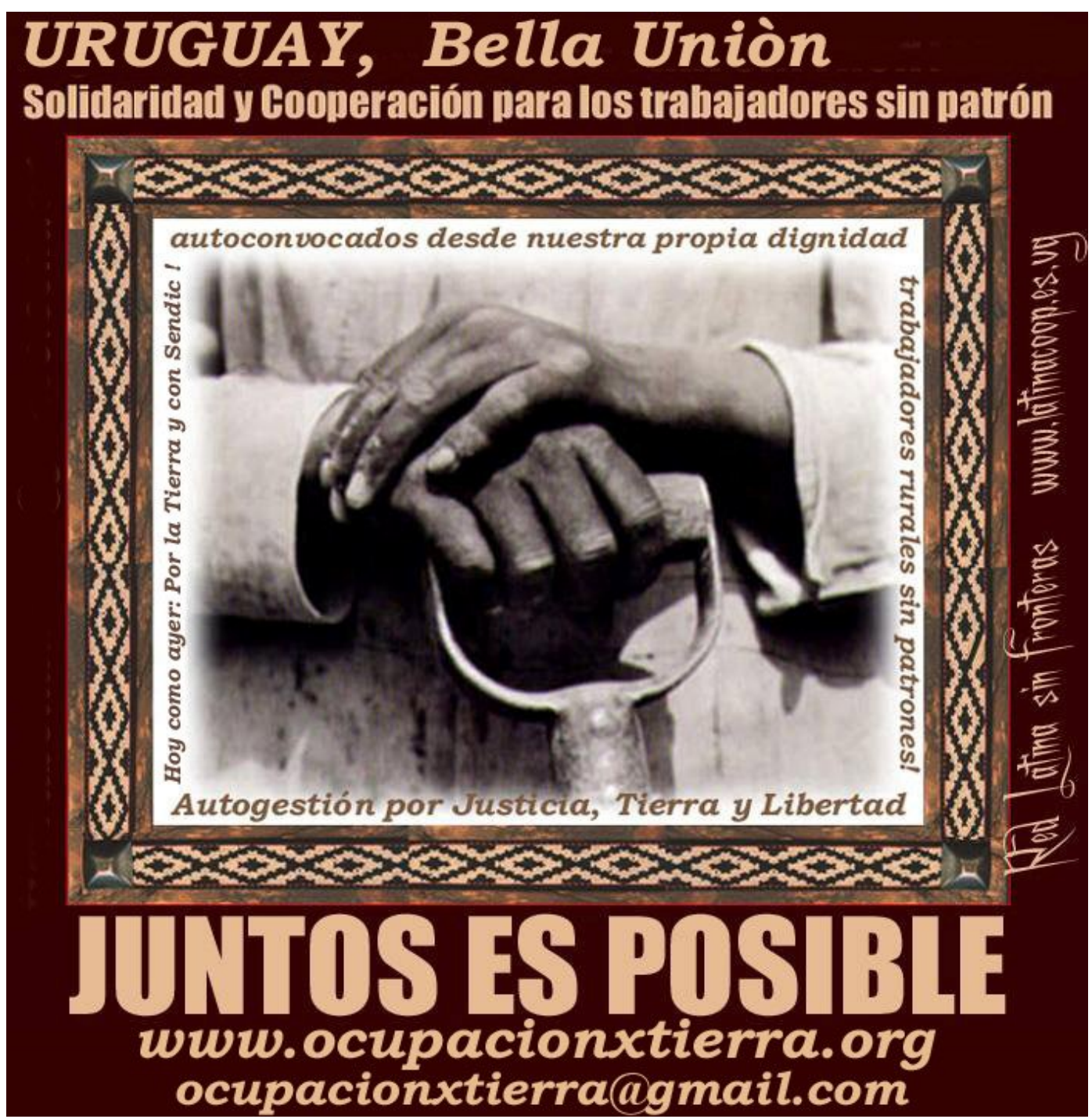

Fuente: http://redlatinasinfronteras. blogspot.com/. Acceso en: 12 oct. 2009.

En estos mensajes en los que la "tierra" parece asumir un alto contenido simbólico las identificaciones propuestas para "los peludos" remiten a un tiempo anterior al Estado- nación (o a otra, como la "gran Nación Charrúa") que posibilita la asociación con el "indio" o "lo indio". Fue una marcación que se instaló decididamente como horizonte de sentido a partir de la ocupación de tierras, específicamente en lo que fue 
la campaña de solidaridad que la acompañó. Veamos uno de los afiches que integró esta campaña y que tuvo una amplia circulación por Internet:

Se trata de una imagen que propone "una interpretación y no una descripción de los hechos" (RIVERA CUSICANQUI, 2010, p. 31). Dominado por colores cálidos que remiten a un hipotético tiempo pasado vinculado a la tierra, el afiche sitúa (“Uruguay, Bella Unión”), explica su objetivo ("Solidaridad y Cooperación para los trabajadores sin patrón") y propone como lograrlo ("Juntos es posible"). El sujeto/objeto de esta solidaridad estaría particularmente representado en el centro, más precisamente en el rectángulo que propone una suerte de madera que, enmarcada por una guarda pampa, muestra una de las fotografías más conocidas de Tina Modotti, tomada en México a fines de la década de 1920. La foto, un primer plano de dos manos curtidas por el trabajo, apoyadas sobre un instrumento de labranza, trae un sujeto anónimo que posibilita las inscripciones propuestas ("autogestión, trabajadores rurales sin patrón" y "autoconvocados desde nuestra propia dignidad") y que interpela, desde una demanda particular: ¿a quiénes? Códigos, reglas y esquemas que buscan incorporar las luchas políticas y a sus protagonistas en un universo de referencias amplio, al alcance de cualquier persona, en cualquier parte del mundo. En esta tarea "lo indio" aparece como una dimensión constitutiva y legitimadora de la demanda pero, nuevamente: ¿para quiénes? ¿para qué?

Entre los destinatarios de esta solidaridad, es decir entre los/as ocupantes que decidieron presentarse como "peludos de Bella Unión", este tipo de imágenes y de mensajes cayeron en una suerte de vacío cultural y político. A diferencia de las fotografías tomadas en la ocupación publicadas en la prensa montevideana que padres y madres recortaban y guardaban como fotos familiares, especialmente si en ellas aparecían sus hijos/as, lo que ocurría en la web les era bastante ajeno. Los mensajes o el afiche que trajimos al análisis no circulaban por ni formaban parte de la ocupación, no eran para los/as ocupantes material de reflexión, ni siquiera pistas en las cuales fundar, justificar o reforzar la opción, posiblemente porque las identificaciones planteadas estaban lejos de la particularización por la que luchaban. Tal vez porque, como ironizó un miembro del INC, en Uruguay "ser indio no rinde". Estando allí, en el predio ocupado, había que hacer grandes esfuerzos para que 
alguno/a de mis interlocutores/as logre identificar de qué les estaba hablando cuando los/as consultaba por estos mensajes o estos afiches. En una oportunidad, una de las ocupantes, se refirió al afiche que trajimos al análisis como "el cuadro de la foto vieja" y, a la guarda pampa, como "dibujito". En los mensajes y el afiche que los/as hablaba, circulando por un mundo ancho, no estaba "lo peludo" para "los peludos". Pero ¿estaba "lo indio"? ¿Debía estarlo? ¿De qué modo?

Quienes protagonizaron la ocupación en ningún momento sostuvieron su reivindicación de tierras en términos de una expropiación colonialista de larga data $y$, mucho menos, se reclamaron como legítimos/as descendientes de sus primeros habitantes. Su marco referencial era otro, era la compleja articulación de su reclamo como "peludos" con sus derechos como "uruguayos". En este terreno, en el que la identificación particular era aportada por los sentidos históricos atribuidos a la palabra "peludo" que reseñamos al comienzo de este texto, y la identificación nacional era aportada por el objetivo que perseguía la medida, "el indio", "lo indio" no sedimentó. Más específicamente, "los peludos" no estaban dispuestos a encarnar a "los charrúas" más que lo que los encarnarían cualquier uruguayo. Pensarse, presentarse y representarse como "charrúa" parecía no aportar a la lucha en la arena de la "sociedad política" pero, para comprender esto, debemos detenernos aunque sea muy brevemente en uno de los modos posibles en que las narrativas nacionales en Uruguay incorporaron esta clave.

\section{Algunos itinerarios de "los charrúas" y "lo charrúa" en el relato nacional hegemónico}

En Uruguay, como en otros países de la región, el juego de inclusión y exclusión del indígena operó alternativamente sobre el relato nacional hegemónico como "hueco" y como "legado blanqueado". Como es sabido, la "garra charrúa" - en calidad de herencia - integra la larga lista de signos diacríticos de la "uruguayidad". Sin embargo, los rasgos étnicos del "charrúa" murieron con "Tabaré" (de 1888) para afirmar, desde la dedicatoria de este texto fundacional, que "blanca (tu raza, 
nuestra raza) ha quedado viva sobre el cadáver del charrúa" (ZORRILLA DE SAN MARTín, 2004, p. 9).

"Tabaré" es el nombre de la novela de Juan Zorrilla de San Martín y el nombre de su personaje principal, el último exponente de una etnia que no llegó a integrarse a la nación, la personificación de una "extirpe muerta" que legó a los uruguayos su indomable bravura y su valentía; lo único válido de ser legado ya que Tabaré es, también, la imagen de un mundo en decadencia que muestra a los indígenas participando de orgías y violaciones, en una eterna indolencia improductiva, como un "oscuro rebaño de culebras" (ZORRILLA DE SAN MARTíN, 2004, p. 172) que ataca a las mujeres españolas, "raza de vírgenes tan pálidas como la flor del lirio" (ZORRILLA DE SAN MARTíN, 2004, p. 141). Con Tabaré, tal como señala la crítica literaria, la etnia indígena quedó marginada de la integración a la comunidad nacional convalidando su opción blanca, europeísta y cristiana (BURGUEÑO, 2000, p. 83).

Pocos años después de la publicación de "Tabaré", para los primeros años del siglo XX, - tras la llegada al Poder Ejecutivo de José Batlle y Ordónez ${ }^{16}$, quien impulsó el proceso de modernización del país incluyendo un modo particular de proyectar la nación e inscribirla en el mundo (cosmopolita, civilizatoria, industrialista y laica) - el relato acuñado por "Tabaré" reformuló la opción "cristiana" en el mito- praxis de la "nación laica" (GUIGOU, 2000), pero no abandonó la opción "blanca" y "europeísta" que forjó el relato sobre la "excepcionalidad uruguaya" en la región. Es decir la idea de una "mentalidad" caracterizada por el privilegio del consenso al conflicto y el estricto respeto a la legislación de avanzada que, entre otras cuestiones, indicó al uruguayo, como un pueblo "cordial", "culto" y "educado": un pueblo "suizo", en América. Es esta última caracterización la que se "mezcla" con el legado "charrúa" en un complejo juego de préstamos e intercambios que, sin embargo, no pretende poner en cuestión el canon creado en y por "Tabaré". Tal vez el fragmento que sigue, parte del cuplé que la reconocida y premiada murga "Agarrate Catalina" presentó en el último carnaval, pueda ayudar explicar esta imbricación de atributos como sutura de tiempos históricos:

\footnotetext{
${ }^{16}$ José Batlle y Ordóñez, presidente de la república en los períodos 1903/07 y 1911/15, fue el iniciador de una saga familiar de políticos. El batllismo designa desde entonces un modo de hacer política y de pensar el Uruguay.
}

Espaço Ameríndio, Porto Alegre, v. 4, n. 2, p. 172-190, jul./dez. 2010. 
Acá estaban los charrúas, pura garra y corazón./ Puro corazón y garra, poca civilización./ No te hacían edificios, ni ninguna construcción./ No tenían calendario, no tenían plantación./ Los más revolucionario, en el plano cultural,/ una cuerda con un palo, era el arco musical./ No tenían sacerdotes, no tenían religión./ No tenían nada, la puta que lo pario./ Pero era un pueblo muy gentil con el que pasaba por ahí./ Eran correctos y educados, hicieron flor de asado cuando llegó Solís (AGARRATE CATALINA, 2010, n./p.).

La mediación batllista confirma la paradoja que plantea "Tabaré" en lo relativo al destino de este "monstruoso engendro a quien feroz la gloria, para besarlo, el corazón arranca". “Tabaré", como no podía ser de otro modo, se enamora de "Blanca", una joven española que lo asiste en su muerte. "Tabaré" muere tras salvar a "Blanca" de su raptor y dejarla a salvo en una playa, señalándole el camino hacia el Uruguay. De este modo, indica la crítica literaria, "el indio otorga posesión a los españoles de su territorio y se crea una imagen en la cual la etnia española recibe al suelo que se convertirá en su patria y, con él, el legado de una etnia indígena que asume plenamente su propia extinción" (BURGUEÑO, 2000, p. 94). Los huesos de "Tabaré" son esparcidos por "Blanca" por llanos, bosques y colinas del suelo uruguayo, allí es donde crecerá el ceibo, cuya flor es uno de los símbolos nacionales.

Pese a lo dicho hasta aquí, este indio, inexistente por inviable pero dueño de algunas virtudes heredadas por todos/as los/as uruguayos/as, no alcanza, no conforma, no es suficiente para traducirse en un relato que pueda descentrar el europeísmo que contribuyó a forjar. El sarcasmo y la acidez que caracteriza a "El Cuarteto de Nos", una de las bandas de culto entre la juventud montevideana, trae la persistencia y el enrome poder de recurrencia de esta narrativa sobre la nación y la tensión que supone imaginar al Uruguay y a sus habitantes como parte de América Latina:

Pensarán que soy medio ladino,/ o que vivo borracho de vino./ Quieren hacerme creer estos cretinos,/ que los uruguayos somos latinos.// Prefiero hablar con un filósofo sueco,/ que con un indio guatemalteco,/ y tengo más en común con un rumano,/ que con un cholo boliviano.// No me jodan más, no somos latinos,/ yo 
me crié acá, en la Suiza del sur (EL CUARTETO DE NOS, 2000, n./p.).

El resultado de esta tensión, o mejor dicho sus consecuencias, aflora sobre el final del cuplé de "Agarrate Catalina", la "garra" revela entonces lo que en rigor es el resultado de un "país asqueroso", un "pueblo enano" y "resentido". "Los charrúas" se despiden cantando:

Parecemos gente tranqui, gente atenta y servicial,/
pero es sólo una apariencia, no se dejen
engañar./Somos muy educaditos, con un aire
intelectual,/ pero adentro reprimimos un asesino
serial./Estamos a la defensiva, con el mundo en
general./Pero con los argentinos, es asunto personal./
Los porteños nos adoran, pero somos gente vil,/y hace
tiempo los odiamos, siempre hinchamos por Brasil.//
Entre Brasil y Argentina la presión nos deformó,/ somos
el gil de la clase, el peor// Un país más resentido y
envidioso no hay,/ chúcaro y acomplejado, pal' turismo
es ideal./Así que si anda pensando, en venir a
veranear,/véngase con la patrona, ibienvenido al
Uruguay! (AGARRATE CATALINA, 2010, n./p.).

A la luz de lo dicho hasta aquí volvamos a la ocupación de tierras en Bella Unión para tratar de explicar por qué la identificación con "el indio", con "lo indio", no sedimentó entre quienes esta vez optaron y persistieron en su (re)presentación como "peludos". Es para ello que habrá que interrogar las relaciones entre la dinámica de la sociedad (política), el particularismo (cultural) y la excepcionalidad (uruguaya).

\section{Palabras finales}

Hace ya varias décadas que la "excepcionalidad uruguaya" se ha desplazado de las narrativas nacionales, que ni los 11 años de dictadura cívico- militar (1973-1985) ni el proceso de integración regional pudieron subvertir, para volverse parte de un "consenso transdisciplinario" indicando un "continuo histórico que se remonta (...) al descubrimiento y la fundación del Estado moderno y la nación" (RICO, 2005, p. 178). La "excepción" resultó y resulta entonces un "dato de la realidad" que ha fundado reflexiones teóricas, incluso entre los más destacados referentes 
culturales e intelectuales. Ceder a la tentación que ejerce su enorme y recurrente poder enunciativo en sus más diversas variantes - sea para señalar al Uruguay como la "Suiza de América" o para indicarlo como un país "feliz", "pequeño", "amortiguador", "híperintegrado", "politicocéntrico", "partidocrático", "estadocéntrico", etc. -, no implica perder de vista las sedimentaciones históricas que hizo a todos/as los/as uruguayos/as portadores/as de las mejores virtudes "charrúas". En cambio implica reconocer que, desde distintos espacios materiales, territoriales culturales y simbólicos, a cada rasgo de "excepcionalidad" le cabe aquello que la cuestiona, aún en casos como el que vimos aquí, en el que los cuestionamientos tienen por móvil o aspiración la incorporación a ella. Es decir, aún cuando desde el particularismo y la fragmentación que demanda la dinámica de la sociedad política no se intenta desmitificar o deslegitimar esta matriz, sino ser abarcado por lo que se cree que implica e, idealmente, promete.

En esta tarea, el parentesco con "el indio", con "lo indio", resultó para "los peludos" una "f(r)icción". Esto es, una representación problemática basada en un doble movimiento interpretativo que, al mismo tiempo que busca establecer una identificación - siempre arbitraria, diría Hall (2006) - como marca distintiva de un grupo social, indica un desajuste con otras identificaciones posibles ${ }^{17}$. "Lo charrúa", "Ios charrúas", no parecería garantizar la participación tal como hoy la entienden "los peludos". Cabe preguntarse, entonces, si la demanda de tierras - y con ella la demanda de inclusión en el "Uruguay productivo" - , "una demanda" que como tituló un semanario por aquellos días, "interpela[ba] a viejos demandantes" (ABELANDO, 2006), podía hacerse apelando a lo que todos/as los/as uruguayos/as poseen o encarnando lo que los/ as denigraría. En su lugar, reclamarse "peludos de Bella Unión", es decir reclamarse como un colectivo particular que revistió con las características de un grupo una demanda que parecía comunitaria,

\footnotetext{
${ }^{17}$ En otra oportunidad he trabajado sobre la definición teórica y empírica de lo que entiendo por "f(r)icción" (MERENSON, 2010). Digamos aquí que, inspirada en Cardoso de Oliveira (1968, entre otros) y Judith Butler (1992 y 1995), cuando pienso en "f(r)icciones" pienso en la doble condición por la que se pretende conocer y reconocer a un grupo social a partir de determinadas marcaciones. Pienso en el juego de representaciones que operan sobre una adscripción creando una "ficción" y una "fricción": "ficción" no como falsead, sino como construcción social, histórica y reguladora, portadora de significado y, "fricción", en tanto implica potenciales tensiones, disputas y desacuerdos de diversos tipos cristalizados en la esfera pública.
}

Espaço Ameríndio, Porto Alegre, v. 4, n. 2, p. 172-190, jul./dez. 2010. 
alcanzó el éxito: una vez concretado el traspaso del ingenio CALNU a la órbita estatal, el nuevo proyecto sucro- alcoholero, ALUR ${ }^{18}$, dependiente de la empresa estatal ANCAP19, compró la caña de azúcar producida en la chacra ocupada dando lugar con ello a la implementación de una de las varias medidas "para- legales" con que el Estado procuró solucionar rápidamente el conflicto. Pero también, el evento reforzó el legado masivo y actualizado iniciado en y con "Tabaré": esa mezcla de "garra" y "educación", de "valentía" y "cordialidad" que finalmente terminaría por revelar la automortificación nacional, percibida como un rasgo tan excepcional que, "como el Uruguay" - según reza el dicho - "no hay".

\section{Referencias bibliográficas}

ABELANDO, Victor. Demandas que interpelan a viejos demandantes. Semanario Brecha, Montevideo, 20 jan. 2006. p. 6-7.

AGARRATE CATAlinA. La Civilización, Cuplé Los Charrúas, Montevideo, 2010. CD-ROM.

ALBO, Xavier. El retorno del Indio. Revista Andina, Cusco, n. 9, p. 299-366, 1991.

BAPTISTA DA SILVA, Sergio et. al. Coletivos indígenas em Porto Alegre e regiões limítrofes. In: GEHLEN, Ivaldo; BORBA SILVA, Marta; DOS SANTOS, Rita (Org.). Diversidade e proteção social: estudos quanti-qualitativos das populações de Porto Alegre. Porto Alegre: Century, 2008. p. 111-166.

BRIONES, Claudia. La alteridad del "cuarto mundo": una deconstrucción antropológica de la diferencia. Buenos Aires: Ediciones del Sol, 1998.

BURGUEÑO, María Cristina. La modernidad uruguaya: imágenes e identidades (1848-1900). Montevideo: Linardi y Risso, 2000.

BUTLER, Judith. Problemas de los géneros, teoría feminista y discurso psicoanalítico. In: NICHOLS, Geraldine (Org.). Feminismo/Posmodernismo. Buenos Aires: Feminaria, 1992. p. 75-95. 1995.

Gender Trouble: feminism and the subversion of identity. London: Routledge,

\footnotetext{
${ }^{18}$ La sigla corresponde a: Alcoholes del Uruguay.

${ }^{19}$ La sigla responde a: Administración Nacional de Combustibles, Alcohol y Portland.
} 
CAETANO, Gerardo; RILLA, José. Historia contemporánea del Uruguay: de la colonia al Mercosur. Montevideo: CLAEH, 1998.

CALHOUM, Craig. Nacionalismo. Buenos Aires: Libros del Zorzal, 2007.

CARDOSO DE OLIVEIRA, Roberto. Problemas e hipóteses relativos á fricção interétnica: sugestões para uma metodologia. América Indígena. México, v. 28, n. 2, p. 339-358, 1968.

CHACRABARTY, Dipesh. Al margen de Europa: pensamiento poscolonial y diferencia histórica. Barcelona: Tusquets, 2008.

CHATTERJEE, Partha. La nación en tiempo heterogéneo y otros estudios subalternos. Lima: IEP/CLACSO/SEPHIS, 2007.

El Cuarteto de Nos, Contramambo, Koala Records, Montevideo, 2000. CD-ROM.

GARCÉ, Adolfo. Donde hubo fuego: el proceso de adaptación del MLN-Tupamaros a la legalidad y a la competencia electoral (1985-2004). Montevideo: Fin de Siglo, 2006.

GRIMSON, Alejandro. Introducción. In: (Org.). Pasiones nacionales: política y cultura en Brasil y Argentina. Buenos Aires: Edhasa, 2007. p. 13-48.

GUIGOU, Lelio. A nação laica: religião civil e mito-praxis no Uruguai. 2000. $207 \mathrm{f}$. Dissertação (Mestrado em Antropologia Social) - Universidade Federal do Rio Grande do Sul, [2000].

HALL, Stuart. A identidade cultural na pós-modernidade. Rio de Janeiro: DP\&A, 2006.

LÁZZARI, Axel. Identidad fantasma: situando las nuevas practices de libertad en el moviento indígena de La Pampa. Quinto Sol, La Pampa, v. 11, n. 11, p. 91-122, 2007.

MERENSON, Silvina. A mi me llaman peludo: cultura, política y nación en los márgenes del Uruguay. 2010. 308 f. Disertación (Doctorado en Ciencias Sociales) IDES/UNGS, [2010].

REAL DE AZÚA, Carlos. Uruguay: ¿una sociedad amortiguadora? Montevideo: Ediciones de la Banda Oriental, 2000.

RICO, Álvaro. Cómo nos domina la clase gobernante: orden político y obediencia social en la democracia posdictadura. Uruguay, 1985-2005. Montevideo: Trilce, 2005.

RIVERA CUSICANQUI, Silvia. Ch'ixinakax utxiwa: una reflexión sobre prácticas y discursos descolonizadores. Buenos Aires: Tinta Limón, 2010.

SEGATO, Rita La Nación y sus otros: raza, etnicidad y diversidad religiosa en tiempos de política de la identidad. Buenos Aires: Prometeo, 2007. 
SIGAUD, Lygia. Armadilhas da honra e do perdão: usos sociais do direito na mata pernambucana. Mana, Rio de Janeiro, v. 10, n. 1, p. 131-163, 2004.

STOLCKE, Verena. De fronteras y mestizajes. In: VENTURA I OLLER, Montserrat et. al. La frontera: entre limits i ponts. Barcelona: Casa América Catalunya, 2006. p. 125137.

TRABAJO y UTOPIA. Buenos Aires, 01 mar. 2006. p. 8.

VICH, Víctor. Presentación. In: CHATERJEE, Partha. La nación en tiempo heterogéneo y otros estudios subalternos. Lima: IEP/CLACSO/SEPHIS, 2007. p. 9-19.

ZORRILLA DE SAN MARTÍN, Juan. Tabaré. Montevideo: Porrúa, 2004. 